\title{
Editorial
}

\section{Branding financial services}

I was delighted to be invited to act as the Guest Editor for this Special Edition on Financial Services Branding. In view of the considerable importance of this sector and the paucity of literature about branding in this sector, the intentions of this Special Edition are to disseminate knowledge from those actively involved in this area and to stimulate further research in this topic.

Branding theory has its roots in the fast moving consumer goods sector. The models of effective brand management tended to stress an external orientation, often focusing on presenting the brand's values as being unique, consumer relevant and capable of some degree of sustainability. There are not as many services organisations which instantly spring to mind as having developed successful service brands. Part of the reason is that the classical physical goods models were applied without sufficient recognition of the intangible nature of service brands and the importance of employees. In the services sector, brand management is much more about an internal orientation which focuses on getting employees to believe in their brand's values and to consistently act in a manner that supports these values. Once this has been achieved, then external considerations are needed about communicating a promise staff can deliver. Service branding is about managing both expectations and perceptions.

The papers in this Special Edition are predominantly from respected practitioners who have sat back from their day-to-day involvement in financial services branding to consider and question what are some of the general principles that characterise the situa- tions they have been working on. Each of the authors brings an informed insight from a rich background of active involvement in financial service branding. From the collection of papers there is much that can be learnt about financial services branding. A few points that cross my mind after reading these papers are:

- Branding in financial services is going to become even more challenging with the advent of e-commerce (from Alan Newman's paper).

- The advent of the Internal Brand Manager is not that far away (from Conrad Free's paper).

- Positioning financial services brands needs to be done based on a sincere organisational attitude - superficial attitudes are quickly seen through (from Lucien Camp's paper).

- Brand positioning is not just about ensuring that consumers value a particular point of difference, it is also about managers translating strategic concepts into the language of all staff so they know what is expected of them (from Ian Farnfield's paper).

I hope these four extracts raise your interest in reading more about the branding of financial services.

This topic will be continued with contributions from Chris Cleaver and Dominic Twose in the next two issues of the journal.

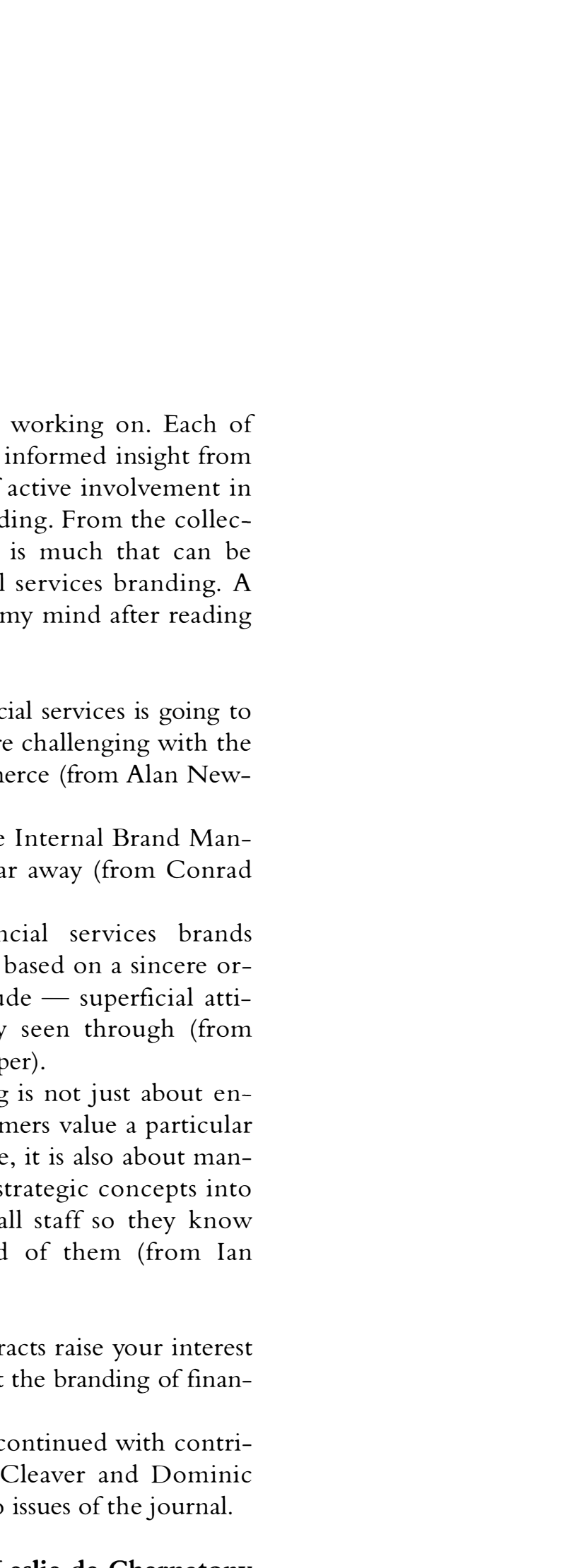

Leslie de Chernatony Editorial Board 